\title{
Basal iridectomy at 6 o'clock in the aphakic eye treated with silicone oil: prevention of keratopathy and secondary glaucoma
}

\author{
W H BEEKHUIS, ${ }^{1}$ F ANDO, ${ }^{2}$ R ŽIVOJNOVIC,' D A E MERTENS, \\ AND E PEPERKAMP' \\ From the 'Department of Ophthalmology, Erasmus University Rotterdam, Eye Hospital, Schiedamsevest 180, \\ 3011 BH Rotterdam, The Netherlands; and the ${ }^{2}$ Department of Ophthalmology, Nagoya University School of \\ Medicine, 65 Tsuruma-cho, Showa-ku, Nagoya, Japan
}

SUMmARY In the aphakic eye, with intact iris diaphragm, silicone oil has frequently caused a pupillary block. In this situation aqueous humour accumulates behind the iris and forces silicone oil through the pupil into the anterior chamber. An iridectomy at the 6 o'clock position can effectively prevent this pupillary block. The iridectomy allows free passage of aqueous to the anterior chamber which remains free of silicone oil. No permanent contact with silicone oil and the cornea is established, and development of keratopathy is prevented. The effect of this iridectomy in 62 eyes with intact iris diaphragm in patients in Rotterdam (35 cases) and Nagoya (27 cases) is demonstrated. Only in $6.5 \%$ of the cases was silicone oil present in the anterior chamber at the end of the follow-up period of 7 months.

Intraocular silicone oil is used for the repair and support of complicated cases of retinal detachment. ${ }^{1-5}$ Complications of silicone oil implantation in detachment surgery have been described. ${ }^{16-8}$ Glaucoma, ${ }^{49}$ cataract, ${ }^{10}$ and corneal opacification $^{10-14}$ are the problems that are encountered most frequently. In the aphakic eye both increased intraocular pressure and corneal opacification may present as serious complications, especially when silicone oil is in permanent contact with the corneal endothelium and chamber angle. Silicone oil keratopathy has been described by us earlier. ${ }^{12}$

This paper describes the advantageous effect of an iridectomy at the 6 o'clock position in the intracapsular aphakic eye to ensure aqueous circulation from the posterior segment to the anterior chamber. Ando started this prevention of pupillary block and thus gave us a solution to separate the silicone oil from the cornea and chamber angle in aphakes. ${ }^{15}$

The results of the 6 o'clock iridectomy in 35 patients treated in Rotterdam, The Netherlands, and 27 patients treated in Nagoya, Japan, are described. For comparison we present the fate of the cornea in 16 patients whose intracapsular aphakic eye had been Correspondence to W H Beekhuis, MD. treated with silicone oil injection and did not have an iridectomy at 6 o'clock. These 16 patients were operated on during the half year preceding the introduction of the 6 o'clock iridectomy.

\section{Patients and methods}

All 62 patients were aphakic at the time of silicone oil injection, had sufficient iris diaphragm left to perform a 6 o'clock iridectomy, and were available for follow-up during the full postoperative period or until the silicone oil was removed from the eye. Patients with an inferior coloboma, aniridia, or incomplete follow-up were excluded from the study. In all patients the iridectomy was performed during the months January to October 1984.

The patients were treated with intraocular silicone oil $(1000 \mathrm{cS})$ for the management of complicated retinal detachment. All patients either had proliferative vitreoretinopathy (PVR), giant tears, or both. Most patients had had previous detachment surgery. In all cases the iridectomy was made at the time of first injection of silicone oil in these aphakic eyes. In 10 cases (Rotterdam three, Nagoya seven) a pars plana lensectomy or intracapsular extraction via a 
corneal incision was performed at the time of surgery. In all other cases the eyes that underwent silicone oil injection and iridectomy at 6 o'clock were aphakic at the time of surgery.

The 6 o'clock iridectomy was performed after the vitrectomy had been completed. The iris base was gently aspirated from the vitreous side into the porthole of the vitrectome and a hole was made. The size of the iridectomy, depending on the shape of the diaphragm, was at least $2 \mathrm{~mm}$ in diameter.

After the vitrectomy and iridectomy, silicone injection was started through the infusion canula in the pars plana. Slow expansion of the oil bubble caused the anterior chamber fluid to be trapped in front of the iris. Sufficient endodrainage by modified flute needle ${ }^{16}$ created space for the pump-driven, footswitch-operated silicone oil injection. The optic nerve vessels were carefully checked for pulsations to prevent pressure rises during silicone oil injection. This also helped to maintain a normal anterior chamber filled with 'aqueous'.

If any oil entered the anterior chamber during injection the surgeon continued the oil injection. Aqueous was drained with a flute needle from the posterior segment until the eye was almost completely filled with oil. Then the anterior chamber was entered by a small canula through the pars plana and through the iridectomy to force the oil down behind the diaphragm with injection of aqueous substitute.

By this method we were generally able to achieve an anterior chamber free from oil at the conclusion of the operation.

\section{Results}

The results are summarised in Table 1.

The Rotterdam material consisted of 35 patients ( 35 eyes). The mean observation time was 7.5 months (ranging from 3 to 14 months). Of 35 cases 33 had a silicone oil face at the level of the pupil or what was left of the diaphragm. At the end of the observation period silicone oil was present in the anterior

Table 1 The cornea and silicone oil: results of $6 o^{\prime}$ clock iridectomy in intracapsular aphakic silicone oil surgery

\begin{tabular}{|c|c|c|c|c|}
\hline \multirow[b]{2}{*}{ Number of cases } & \multicolumn{3}{|c|}{$\begin{array}{l}\text { Rotter- Nagoya Total } \\
\text { dam }\end{array}$} & \multirow{2}{*}{$\begin{array}{c}\% \\
100\end{array}$} \\
\hline & 35 & 27 & 62 & \\
\hline Oil in anterior chamber & 2 & 2 & 4 & $6 \cdot 5$ \\
\hline Iridectomy initially closed & 6 & 4 & 10 & $16 \cdot 1$ \\
\hline Iridectomy permanently closed & 5 & 4 & 9 & $14 \cdot 5$ \\
\hline IOP $>21 \mathrm{mmHg}$ without medication & 5 & 4 & 9 & $14 \cdot 5$ \\
\hline IOP $>21 \mathrm{mmHg}$ with medication & 0 & 0 & 0 & 0 \\
\hline Corneal opacification & 2 & 4 & 6 & $9 \cdot 7$ \\
\hline
\end{tabular}

chamber in contact with the corneal endothelium in two cases.

In one of these two cases the iridectomy had closed at three months postoperatively for unknown reasons, and the intraocular pressure was raised to 25 $\mathrm{mmHg}$. The condition of the posterior segment allowed oil removal after six months. The visual acuity of this eye that had PVR in high myopia remained $0 \cdot 15$. The second case with an oil filled anterior chamber had an open iridectomy. The mechanism of aqueous flow through the iridectomy did not function properly because of a large choroidal effusion in the lower quadrants, by which means the aqueous was probably diffusing from the eye instead of by the chamber angle.

At the end of the follow-up period the 6 o'clock iridectomy was closed in five eyes. In one case, as mentioned above, oil was in the anterior chamber. In the remaining four cases, however, no oil was present in the anterior chamber.

In the early postoperative period six iridectomies were closed owing to fibrin or a blood clot. In five of these cases the iridectomy opened spontaneously in two to eight weeks and in one case the iridectomy was reopened with YAG laser, whereupon the oil disappeared from the anterior chamber. In five cases an increase in intraocular pressure to $32 \mathrm{mmHg}$ was noted during the follow-up. All cases could be regulated medically to pressures lower than 21 mmHg. Two patients had a slight band-shaped keratopathy without oil in the anterior chamber. No other silicone oil related corneal opacities were registered.

The Nagoya material contained 27 patients (27 eyes). The mean observation time was $7 \cdot 0$ months, ranging from 3 to 13 months. Of 27 cases 25 had an anterior chamber free of silicone oil. In four cases the iridectomy closed. Two cases had rubeosis iridis, which could explain excessive fibrin clotting, and in the two other cases the iridectomy had been too small.

At the end of the observation period silicone oil was present in the anterior chamber of two of the Nagoya cases: one being a patient with rubeosis iridis and one more case with open iridectomy without further particulars.

Intraocular pressure was elevated over $21 \mathrm{mmHg}$ in four cases, but was regulated within normal limits medically. A slight band-shaped keratopathy was noted in four cases.

\section{COMPARISON WITH CASES FROM PREIRIDECTOMY} ERA

To substantiate our impression that a 6 o'clock iridectomy can prevent complications in the silicone oil filled intracapsular aphakic eye we have reviewed 
all the charts of vitrectomy patients in whom silicone oil was utilised during the last half year preceding the introduction of the 6 o'clock iridectomy. The period thus studied was July through December 1983 . We selected all consecutive intracapsular aphakic cases that had an intact or almost intact iris diaphragm and had sufficient follow-up.

Thus, from the Rotterdam material we reviewed 16 cases. The findings are summarised in Table 2 . In only five cases did the cornea remain clear. In the other 11 cases either a band-shaped keratopathy or vascularisation and stromal swelling slowly developed as a result of presence of silicone oil in the anterior chamber, mostly in permanent contact with the corneal endothelium.

Of those having a clear cornea, one patient had an anterior chamber full of vitreous protecting the cornea from entrance of the silicone oil. One diabetic patient had a thin membrane in the pupil resulting in a seclusio pupillae on the anterior silicone oil bubble's face. So only three patients were found to have a clear cornea without silicone oil in the anterior chamber without any additional circumstances that supported the retropupillary position of the oil bubble.

Of those 11 cases that developed keratopathy four received a corneal transplant within our follow-up period (up to January 1986). In two cases a secondary 6 o'clock iridectomy was performed and resulted in disappearance of oil from the anterior chamber. The other patients underwent several abrasions and disodium-EDTA treatment to remove the bandshaped keratopathy before the oil could be removed from the eye. In two cases no treatment for the corneal opacification was undertaken because of the bad prognosis of the PVR process within the eye, which did not warrant penetrating keratoplasty.

\section{Discussion}

The effect of successful application of silicone oil in the management of retinal detachment in the aphakic eye has until now been seriously hampered by

Table 2 The cornea and silicone oil: results without 6 o'clock iridectomy in intracapsular aphakic silicone oil surgery

\begin{tabular}{lr}
\hline Number of cases & 16 \\
Clear cornea: & 5 \\
vitreous in anterior chamber & 1 \\
pupillary seclusion & 1 \\
Keratopathy: & 11 \\
Na-EDTA treated & 3 \\
keratoplasty performed & 4 \\
secondary iridectomy & 2 \\
'accepted' & 2 \\
\hline
\end{tabular}

corneal opacification and secondary pressure rises. Permanent contact of silicone oil with endothelium of the cornea is thought to be the cause of these two major complications of intraocular silicone oil. The results of the use of a 60 'clock iridectomy are clearly demonstrated by the material presented. In the group of patients with an iridectomy at 6 o'clock (62 cases) only $10 \%$ of patients developed corneal opacification, and in none of these was a corneal graft needed. In the smaller group (16 cases) that is presented for comparison, which did not have a 6 o'clock iridectomy, the majority of cases $(69 \%)$ had corneal trouble, either band-shaped keratopathy or corneal decompensation. From these results the advantage of a 6 o'clock iridectomy is obvious.

The mechanism by which a 6 o'clock iridectomy prevents silicone oil from entering the anterior chamber is explained as follows. By cohesive forces the silicone oil bubble tends to take on a smooth spherical form within the aqueous filled posterior segment of the vitrectomised aphakic eye. Silicone oil will not enter the anterior chamber as long as it does not create a pupillary block (Fig. 1). With an existing pupillary block the aqueous will accumulate behind the iris diaphragm at the lowest part of the posterior segment. During waking hours this is at the 6 o'clock position behind the iris. Pressure building up by aqueous production forces silicone oil through the pupil and results in an oil filled anterior chamber. An iridectomy at the 6 o'clock position prevents a pupillary block and ensures passage of aqueous towards the chamber angle (Fig. 2). An iridectomy at the 12 o'clock position is less likely to solve the problem because the silicone oil bubble is directly behind the iris and is floating against the diaphragm in the upper part of the eye.

The fact that in a few of our cases no oil was present in the anterior chamber while the iridectomy appeared to be closed is explained as follows. When
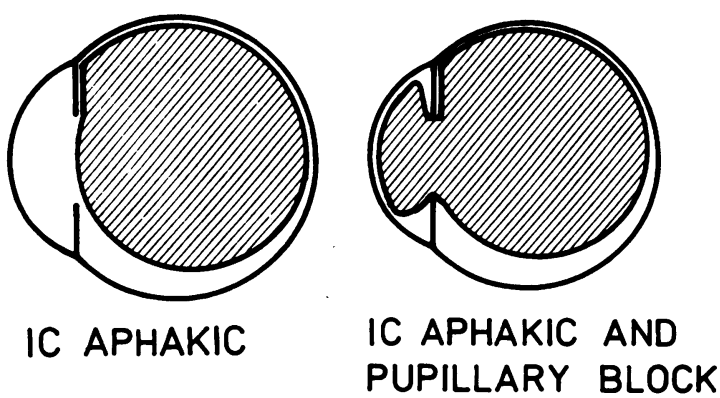

Fig. 1 Left: silicone oil fills the posterior segment, aqueous passage towards the anterior chamber is patent. Right: $a$ slightly larger quantity of oil causes pupillary block, and silicone oil is forced into the anterior chamber. IC = intracapsular. 
Fig. 2 Left: an iridectomy at the 6 o'clock position allows aqueous flow towards the anterior chamber. Right: the oil bubble retracts towards spherical shape as soon as the pupillary block is broken or prevented.

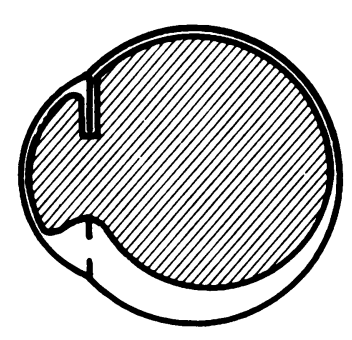

IRIDECTOMY PREVENTS BLOCK

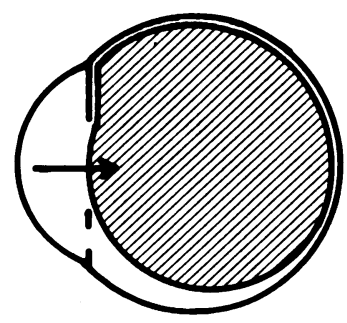

COHESIVE FORCES PRODUCE ONE OIL BUBBLE WHEN AQUEOUS FLOW IS SUFFICIENT the posterior segment is not filled completely with silicone oil, the oil bubble is not large enough to cause a complete pupillary block. The lower part of the diaphragm is free of contact with the silicone oil, and aqueous from under the bubble can move into the anterior chamber (Fig. 1, left diagram).

The 6 o'clock iridectomy described here was performed as a primary procedure. However, the iridectomy can be made as a secondary intervention.

Failure of a 6 o'clock iridectomy to achieve an anterior chamber free of silicone oil may have three causes. Either the iridectomy had been too small or the production of aqueous humour had been too low to circulate sufficiently into the anterior chamber. Some eyes with complicated retinal detachment which had multiple surgery, including encircling procedures and cryocoagulation, have a low aqueous turnover rate. The presence of silicone oil, pressing against the ciliary body processes may further decrease aqueous production.

A third cause for the presence of silicone oil in the anterior chamber while the 6 o'clock iridectomy is open is the occurrence of a traction detachment that decreases the volume of the vitreous cavity. Appearance of silicone oil in an anterior chamber that previously was free from oil should alert the surgeon to the possibility of a recurrence of a traction detachment.

An iridectomy at the 6 o'clock position as a routine addition to silicone oil surgery in the aphakic eye has drastically prevented serious anterior chamber complications in our group of patients.

1 Scott JD. A rationale for the use of liquid silicone. Trans Ophthalmol Soc UK 1977; 97: 235-7.
2 Živojnović R, Mertens DAE, Baarsma GS. Das flüssige Silikon in der Amotiochirurgie. Klin Monatsbl Augenheilkd 1981; 179: 17-22.

3 Živojnović R, Mertens DAE, Peperkamp E. Das flüssige Silikon in der Amotiochirurgie (II). Bericht über. 280 Fälle, weiterre Entwicklung der Technik. Klin Monatsbl Augenheilkd 1982; 181: 444-52.

4 Leaver PK, Grey HB, Garner A. Silicone injection in the treatment of massive preretinal retraction. II. Late complications in 93 eyes. Br J Ophthalmol 1979; 63: 361-7.

5 Grey RHB, Leaver PK. Silicone oil in the treatment of massive preretinal retraction. I. Results in 105 eyes. $\mathrm{Br} \mathrm{J} \mathrm{Ophthalmol}$ 1979; 63: 355-60.

$6 \mathrm{Ni} \mathrm{C}$, Wang WJ, Albert MD, Schepens CL. Intravitreous silicone injection. Histopathologic findings in a human eye after 12 years. Arch Ophthalmol 1983; 101: 1399-401.

7 Laroche L, Pavakis C, Saraoux H, Orcel L. Ocular findings following intravitreal silicone injection. Arch Ophthalmol 1983; 101: $1422-5$.

8 Blodi FC. Injection and impregnation of liquid silicone into ocular tissues. Am J Ophthalmol 1971; 71: 1044-51.

9 Watzke RC. Silicone retinopiesis for retinal detachment. Arch Ophthalmol 1967; 77: 185-96.

10 Cockerham WD, Schepens CL, Freeman HM. Silicone injection in retinal detachment. Arch Ophthalmol 1970; 83: 704-12.

11 Cibis PA, Becker B, Okun E, Canaan S. The use of liquid silicone in retinal detachment surgery. Arch Ophthalmol 1962; 68: 590-9.

12 Beekhuis WH, van Rij G, Živojnović R. Silicone oil keratopathy: indications for keratoplasty. BrJ Ophthalmol 1985; 69: 247-53.

13 MacRae S, Matsuda M, Edelhauser $H$. The effect of viscous silicone on the anterior segment. Invest Ophthalmol Vis Sci 1984; 25(suppl): 322.

14 Sternberg P, Hatchell DL, Foulks GN, Landers MB. The effect of silicone oil on the cornea. Arch Ophthalmol 1985; 103: $90-4$.

15 Ando $F$. Intraocular hypertension resulting from pupillary block by silicone oil. Am J Ophthalmol 1985; 99: 87-8.

16 Živojnović R, Vijfvinkel GJ. A modified flute needle. Am J Ophthalmol 1983;96: 548-9.

Accepted for publication 29 May 1986. 